(c) American Dairy Science Association, 2004.

\title{
The DGAT1 K232A Mutation Is Not Solely Responsible for the Milk Production Quantitative Trait Locus on the Bovine Chromosome 14
}

\author{
J. Bennewitz, ${ }^{1}$ N. Reinsch, ${ }^{2}$ S. Paul, ${ }^{1}$ C. Looft, ${ }^{1}$ B. Kaupe,${ }^{3}$ C. Weimann, ${ }^{3}$ \\ G. Erhardt, ${ }^{3}$ G. Thaller, ${ }^{4}$ Ch. Kühn, ${ }^{2}$ M. Schwerin, ${ }^{2}$ H. Thomsen, ${ }^{5}$ \\ F. Reinhardt, ${ }^{5}$ R. Reents, ${ }^{5}$ and E. Kalm ${ }^{1}$ \\ ${ }^{1}$ Institut für Tierzucht und Tierhaltung, Christian-Albrechts-Universität, \\ D-24098 Kiel, Germany \\ ${ }^{2}$ Forschungsinstitut für die Biologie landwirtschaftlicher Nutztiere, \\ D-18196 Dummerstorf, Germany \\ ${ }^{3}$ Institut für Tierzucht und Haustiergenetik der Justus-Liebig-Universität, \\ D-35390 Gießen, Germany \\ ${ }^{4}$ Lehrstuhl für Tierzucht, Technische Universität München, \\ D-85354 Freising, Germany \\ ${ }^{5}$ Vereinigte Informationssysteme Tierhaltung w.V., \\ D-27283 Verden, Germany
}

\begin{abstract}
The gene, acyl-CoA:diacylglycerol acyltransferase 1 (DGAT1), was recently identified as the one underlying the quantitative trait locus (QTL) for milk production traits in the centromeric region of the bovine chromosome 14. Until now, 2 alleles, the lysine variant (increasing fat yield, fat and protein percentage) and the alanine variant (increasing protein and milk yield), were postulated at DGAT1. This study investigated whether the diallelic DGAT1 polymorphism is responsible for all the genetic variation at the centromeric region of this chromosome for milk, fat, and protein yield and fat and protein percentage. A statistical model was applied to a granddaughter design to analyze 16 German Holstein families. The model included the diallelic DGAT1 effect and the QTL transition probability estimated for each chromosomal position by a multiple marker approach. Because the regression coefficient of this probability was corrected for the diallelic DGAT1 polymorphism, it represented a putative conditional QTL effect. The effect of the DGAT1 gene was always highly significant. The conditional QTL effect was significant genomewise for fat percentage at the proximal end of the chromosome and for protein percentage at a more distal chromosomal region. Additional chromosomewise significance was found for fat and protein yield. Our results suggest an additional source of genetic variance on this chromosome for these traits; either one or more additional alleles segregating at
\end{abstract}

Received June 23, 2003.

Accepted September 14, 2003.

Corresponding author: J. Bennewitz; e-mail: jbennewitz@tierzucht. uni-kiel.de.
DGAT1 that were not previously detected, a second quantitative trait locus affecting these traits, or both. (Key words: DGAT1, multiple allele, quantitative trait locus, dairy cattle)

Abbreviation key: DGAT1 = acyl-CoA:diacylglycerol acyltransferase1, DYD = daughter yield deviation, K232A = lysine to alanine substitution.

\section{INTRODUCTION}

Mapping QTL for continuous traits of economical importance in livestock species is a frequently used application of genetic markers. In dairy cattle, emphasis was put mostly on the 5 milk production traits: milk yield, fat yield and percentage, and protein yield and percentage. For all milk production traits, various QTL have been found (reviewed by Bovenhuis und Schrooten 2002). A major QTL for all milk production traits, especially for milk fat percentage in the proximal region of chromosome 14, was reported by Coppieters et al. (1998) and Heyen et al. (1999). In subsequent studies this QTL was first fine-mapped by Riquet et al. (1999) and later by Farnir et al. (2002), who revised the estimated QTL location postulated by Riquet et al. (1999) and mapped this QTL proximal to the marker ILSTS039. Meanwhile Looft et al. (2001) mapped the expressed sequence tag KIEL_E8 derived from mammary gland tissue of a lactating cow proximal to ILSTS039 (estimated recombination rate 1\%). The authors detected a linkage disequilibrium between the diallelic KIEL_E8 and the QTL for the 3 milk yield traits, one allele increased milk yield and protein yield and the other allele increased fat yield.

Recently, Winter et al. (2002) and Grisart et al. (2002) independently identified the acyl-CoA:diacylglycerol 
acyltransferase1 (DGAT1) gene as a strong candidate gene for the QTL for milk production traits in the proximal region of chromosome 14 . The DGAT1 gene encodes an enzyme that plays a central role in the synthesis of triglycerides. It catalyzes the reaction of diacylglycerol and fatty acyl-CoA to form triglycerides. Both studies mapped DGAT1 close to the region of the QTL for milk production traits on the bovine chromosome 14 mentioned above and found a nonconservative substitution of lysine by alanine (K232A) in DGAT1 caused by an adenine/adenine to guanine/cytosine dinucleotide substitution at position 10433 and 10434, respectively, in exon number VIII.

The DGAT1 effects in the New Zealand and in the Dutch Holstein dairy cattle population were estimated by Grisart et al. (2002), in the New Zealand Holstein dairy cattle population by Spelman et al. (2002), and recently, in the German Holstein dairy cattle population by Thaller et al. (2003). All authors reported a strong allele substitution effect on milk, fat, and protein yield indicating that DGAT1 is a major gene. The lysine variant increased fat yield and decreased protein and milk yield, the alanine variant affected these traits in an opposite direction compared to the lysine variant. The mode of inheritance is almost completely additive (Grisart et al., 2002), the allele frequency of the lysine variant in the German Holsteins was estimated to be 0.53 (Thaller et al., 2003).

From other major genes it is known that in general more than 2 alleles are segregating at a particular locus. For example, at the Extension $(E)$ locus, identified as the melanocyte-stimulating hormone $(M S H)$ receptor locus (Robbins et al., 1993) and responsible for most of the variation of cattle coat colour, three alleles are known. These are $E^{D}$ (dominant black), $E^{+}$(combination of black and red), and $e$ (recessive red). At the $m h$ locus, causing double-muscling in cattle, Georges et al. (1998) reported at least 5 different alleles with impact on the trait. However, until now only two alleles were reported at the DGAT1 locus.

In the present study, our objective was to determine whether there exists an additional source of genetic variance attributable to genes and/or QTL on chromosome 14 for the traits milk, fat and protein yield, and fat and protein percentage besides the diallelic DGAT1 effect K232A.

\section{MATERIALS AND METHODS}

\section{Animals}

The pedigrees utilized were part of the granddaughter design of the common QTL mapping project of German AI and breeding organizations, several German animal breeding institutes and animal computing cen- ters. These are described in detail by Thomsen et al. (2000). It included 16 German Holstein families with a total of 872 progeny tested bulls. The family size varied between 19 and 127 with an average of 54 sons. Additionally, 3 great-grandsires were included that genetically linked 3, 5, and 6 sires as half-sibs, respectively. The same 16 families were used by Thaller et al. (2003).

\section{Genotypes and Phenotypes}

The families were genotyped for 8 microsatellite markers, as well as the KIEL_E8 and DGAT1 polymorphisms. Microsatellite and KIEL_E8 genotypes were determined by automated fragment analysis (A.L.F., Amersham-Pharmacia or ABI377, Perkin-Elmer). Genotyping at the DGAT1 locus was carried out by a PCRRFLP test based on the K232A substitution in DGAT1 (Kaupe et al., unpublished), the lysine variant was denoted as the $\mathrm{Q}$ allele. The genotypes were checked for their agreement with the Mendelian laws of inheritance and conflicts were solved, if possible. The marker data were stored in the ADRDB database (Reinsch, 1999). Multipoint marker maps were computed using CRIMAP (Green et al., 1990). The marker order is as follows (estimated distances from the first marker in cM estimated by the Kosambi mapping function are in parentheses): KIEL_E8 (0.0), DGAT1 (0.3), ILSTS039 (1.3), CSSM66 (8.7), RM180 (41.5), RM11 (56.5), BM4630 (57.6), RM192 (75.8), BM4513 (113.3), and BL1036 (139.8). Note that the TWOPOINT option of CRIMAP, which considers only two particular loci at a time (Green et al., 1990), estimated a recombination rate of 0\% (lod score 69.42) between KIEL_E8 and DGAT1. The marker order is in agreement with previously published marker maps (e.g., Kappes et al., 1997). For a more detailed description of the markers and the genetic map see Thomsen et al. (2000).

The following 5 traits were considered: milk yield, fat yield, protein yield, fat percentage, and protein percentage of the milk. For the 3 yield traits, daughter yield deviations (DYD) were calculated from the production records of the daughters. The DYD are the average phenotypes of daughters, corrected for fixed effects and the genetic contribution of the daughter's dam and were obtained as by-products from the routine national sire evaluation. The DYD were calculated for the first lactation and as a weighted average for the first 3 lactations. The latter yield trait estimates were slightly more variable than the estimates for the first lactation only. No DYD were available for the 2 percentage traits, therefore deregressed estimated breeding values were used. The deregressed values were obtained by dividing the estimated breeding value by the square of its reliability. 
Table 1. Description of the phenotypic parameters and the heritability for each trait as provided by the national animal computing center.

\begin{tabular}{lllllll}
\hline Trait $^{1}$ & Unit $^{2}$ & Mean & SD & Minimum & Maximum & Heritability $^{3}$ \\
\hline MY1L & DYD & 262 & 256 & -722 & 1177 & 0.295 \\
MY1-3L & DYD & 283 & 267 & -743 & 1131 & 0.255 \\
FY1L & DYD & 7.98 & 9.04 & -20.32 & 35.81 & 0.254 \\
FY1-3L & DYD & 8.59 & 9.53 & -19.13 & 47.36 & 0.212 \\
PY1L & DYD & 6.97 & 6.87 & -21.77 & 28.31 & 0.248 \\
PY1-3L & DYD & 7.77 & 7.41 & -22.32 & 32.65 & 0.226 \\
FP & DRBV & -0.04 & 0.27 & -0.84 & 0.71 & $\ldots$ \\
PP & DRBV & -0.03 & 0.11 & -0.49 & 0.27 & $\ldots$ \\
\hline
\end{tabular}

${ }^{1}$ MY1L (FY1L, PY1L) milk yield (fat yield, protein yield) first lactation, MY1-3L (FY1-3L, PY1-3L) milk yield (fat yield, protein yield) first to third lactation, FP fat percentage, PP protein percentage.

${ }^{2}$ Unit of measurement: DYD daughter yield deviation in kg per lactation (305 days), DRBV deregressed estimated breeding values in percent.

${ }^{3}$ No heritabilities were available for the 2 percentage traits from the national animal computing center.

The DYD and the estimated breeding values were taken from the routine national sire evaluation in February 2001 and in February 2003, respectively, no DYD were available from February 2003. For a more detailed description of the phenotypes and genetic parameters of the traits as used for the national sire evaluation see Table 1.

\section{Statistical Analysis}

Three different regression models were applied. The first model was the classical multimarker regression (Knott et al., 1996), performed across all families. For each $\mathrm{cM}$ on the chromosome the phenotypes were regressed on the corresponding QTL transition probabilities representing a putative QTL effect by using the following model:

$$
\mathrm{y}_{\mathrm{ij}}=\mathrm{gs}_{\mathrm{i}}+\mathrm{b}_{\mathrm{ik}} \times \mathrm{tp}_{\mathrm{ijk}}+\mathrm{e}_{\mathrm{ijk}},
$$

where $y_{i j}$ is the phenotype of $j$ th sire of the $i$ th grandsire, $\mathrm{gs}_{\mathrm{i}}$ is the fixed effect of the $i$ th grandsire, $\mathrm{b}_{\mathrm{ik}}$ is the regression coefficient for the $i$ th grandsire at the $k$ th chromosomal location, $\mathrm{tp}_{\mathrm{ijk}}$ is the probability of the $j$ th sire receiving the chromosomal segment for gamete one (gamete numbers were randomly assigned) from the $i$ th grandsire at the $k$ th chromosomal position, and $\mathrm{e}_{\mathrm{ijk}}$ is the random residual. A weighted regression was performed for the yield traits. The corresponding weights were one over the variance of the DYD. For the derivation of the formulas see appendix A. An unweighted regression was performed for the 2 percentage traits. The QTL transition probabilities were calculated for each $\mathrm{cM}$ and each progeny with the software BIGMAP (Reinsch, 1999), the regression was performed using the software ADRQLT (Reinsch, 1999).

The respective null hypothesis is that no QTL segregates on the chromosome 14 , i.e., $\mathrm{H}_{0}: b_{i k}=0$. The alter- native hypothesis is that a QTL segregates on this chromosome, i.e., $\mathrm{H}_{1}: b_{i k} \neq 0$. To account for multiple testing, test statistic critical values for the QTL effect were calculated for each trait separately by the use of the permutation test (Churchill and Doerge, 1994). Briefly, by shuffling the phenotypic data 10,000 times randomly while keeping the marker data constant, the genotypephenotype association was uncoupled and, hence, after applying the mapping procedure every QTL estimate indicated a type I error by definition. The chromosomewise critical values $\alpha=1,5$, and $10 \%$ were calculated by taking the 99th, 95th, and 90th quantile from the corresponding distribution of the test statistic, respectively. To aim a situation of a whole genome scan with 30 chromosomes, genomewise error probabilities were calculated from the corresponding chromosomewise error probabilities using the Bonferroni correction:

$$
\mathrm{P}_{\text {genomewise }}=1-\left(1-\mathrm{P}_{\text {chromosomewise }}\right)^{30} .
$$

Model 1 provided only information about whether a QTL is segregating for these traits in this design and was used only for comparison purposes for the following model.

The second model regressed the phenotypes on 2 regression variables. The first was the number of copies of the lysine alleles at the diallelic DGAT1 polymorphism, and the second was the QTL transition probability as described above. The following model was applied:

$$
\mathrm{y}_{\mathrm{ij}}=\mathrm{gs}_{\mathrm{i}}+\mathrm{b}_{1} \times \mathrm{x}_{\mathrm{ij}}+\mathrm{b}_{\mathrm{ik}} \times \mathrm{tp}_{\mathrm{ijk}}+\mathrm{e}_{\mathrm{ijk}}
$$

where $x_{i j}$ is the number of lysine alleles $(0,1$, or 2$)$, $b_{1}$ is the corresponding regression coefficient and the remaining terms are as described in (1). The regression coefficient of the QTL transition probability represented an effect that was corrected for the diallelic 
DGAT1 and is henceforth denoted as a conditional QTL effect. Again, a regression was performed for each cM on the chromosome using the software ADRQLT (Reinsch, 1999) with same weights as used in the first model. From Thaller et al. (2003) we know that the diallelic DGAT1 polymorphism is significant in this experimental design for all traits investigated here. Therefore, the respective null hypothesis is that the diallelic DGAT1 polymorphism shows a significant effect, but the second regression term is not significant. That is, all the genetic variance due to this chromosome was explained by the diallelic DGAT1 polymorphism, and the null hypothesis is $\mathrm{H}_{0}: b_{1} \neq 0$ and $b_{\mathrm{ik}}=0$. The alternative hypothesis is that besides the 2 alleles of DGAT1 there must be another source of genetic variation attributable to this chromosome. Thus, the alternative hypothesis is $\mathrm{H}_{1}$ : $\mathrm{b}_{1}$ $\neq 0$ and $b_{\mathrm{ik}} \neq 0$.

The position with the highest test statistic of the conditional QTL effect was taken as the estimated position of a putative QTL that goes beyond the diallelic DGAT1 effect. Chromosomewise error probabilities were calculated by the permutation test. In contrast to model (1), the QTL transition probabilities were shuffled 10,000 times while keeping the phenotypic data constant. By doing this, the marker genotype-phenotype association was uncoupled but the DGAT1-phenotype association was kept intact. After applying the QTL analysis, every estimate for the conditional QTL effect indicated a type 1 error per definition. Test statistic critical values were then calculated as described above. In addition, the estimated QTL positions from the evaluated permutations were recorded for permutation bootstrapping. Again, to focus on the situation of a whole genome scan, genomewise error probabilities were calculated from the corresponding chromosomewise error probabilities using the Bonferroni correction described above.

For the second model (2), confidence intervals for the estimated positions of putative conditional QTL were computed by permutation bootstrapping (Bennewitz et al., 2002), performing 250 bootstrap samples. The distributions of the 250 QTL position estimates from the evaluated bootstrap samples along the chromosome were corrected for the marker impact using the distributions of the conditional QTL position estimates from the corresponding evaluated permutations. From the marker corrected distributions noncentral 95\% confidence intervals were computed as described by Bennewitz et al. (2002).

The third model focused only on the estimated position of DGAT1 (i.e., at the first position of the chromosome). It regressed the phenotypes on the number of lysine copies at the DGAT1 locus, on the QTL transmission probability (i.e., the conditional QTL effect) at that particular position $\mathrm{k}(\mathrm{k}=0 \mathrm{cM})$, and it included a third variable due to KIEL_E8. Because the diallelic marker KIEL_E8 showed a linkage disequilibrium with the QTL (Looft et al., 2001), it was possible to include the probability of each offspring $\mathrm{j}$ inheriting the KIEL_E8 marker allele " 1 " from the population via the maternal path (tp_pop $\mathrm{ij}_{\mathrm{ij}}$ ) as a regression term:

$$
\begin{aligned}
y_{i j}=g s_{i} & +b_{1} \times x_{j i}+b_{i k} \times t p_{i j k}+b_{2} \\
& \times t_{\text {tp_pop }}+e_{i j}+e_{i j k} .
\end{aligned}
$$

The values of tp_pop are either zero or one when it could be determined with certainty whether the individual received the marker allele "1" from the population pool. Otherwise, it was equal to 0.42 if the inheritance of the marker allele "1" could not be determined. This value was the allele frequency of the allele "1" of KIEL_E8, estimated with a maximum likelihood approach (Appendix B). The respective null hypothesis is that all the genetic variance due to this chromosomal position was explained by the diallelic DGAT1 effect $\left(\mathrm{H}_{0}: \mathrm{b}_{1} \neq 0\right.$ and $b_{\mathrm{ik}}=b_{2}=0$ ). The alternative hypothesis is that the 2 alleles of DGAT1 do not explain all of the genetic variance at this chromosomal position, and hence, the conditional QTL effect and/or the KIEL_E8 regression term will show significant effects as well $\left(\mathrm{H}_{1}: \mathrm{b}_{1} \neq 0\right.$ and $\mathrm{b}_{\mathrm{ik}}$ $\neq 0$ and/or $b_{2} \neq 0$ ). For example, a significant effect of the KIEL_E8 regression term might appear if there is at least a third allele segregating at the DGAT1 locus that is in linkage disequilibrium with one allele of KIEL_E8. A significance of the conditional QTL effect might occur if either a third allele is segregating or at least one sire is heterozygous for a second QTL that is in close linkage with DGAT1. Again, a weighted analysis was performed for the yield traits. The analysis was done using the GLM procedure of the SAS package (SAS Inst., Inc., Cary, NC).

The advantage of model 3 over model 2 is that it utilized all available information at this chromosomal region (i.e., diallelic DGAT1 polymorphism, information of genetic markers via QTL transition probability and the linkage disequilibrium of KIEL_E8 and the QTL). On the other hand, only model 2 allowed examination of all positions of this chromosome, and hence, detection of further putative conditional QTL.

Average allele effects of the lysine allele of DGAT1 were estimated first by model 2 at position $0 \mathrm{cM}$ and then by a model where only DGAT1 was included besides the fixed effect of the grandsire (model not shown). Because of the applied granddaughter design, the regression coefficient of the number of lysine alleles at DGAT1 represented one half of the average allele substitution effect in both models (Falconer and MacKay, 1996) for the yield traits and the full average allele 
Table 2. Average allele substitution effects $(\alpha)$ with standard errors (SE) estimated by 2 different models and the proportion of variance explained by the 2 models (p).

\begin{tabular}{|c|c|c|c|c|c|c|c|c|c|c|}
\hline \multirow{3}{*}{$\begin{array}{l}\text { Model: } \\
\text { trait }^{1}\end{array}$} & \multicolumn{5}{|c|}{ DGAT1 included } & \multicolumn{5}{|c|}{$\begin{array}{l}\text { DGAT1 and conditional QTL effect at } \\
\text { position } 0 \mathrm{cM} \text { included }\end{array}$} \\
\hline & \multicolumn{2}{|c|}{ in $\mathrm{kg}$ or $\%^{2}$} & \multicolumn{2}{|c|}{ in $\sigma_{\mathrm{a}}^{3}$} & \multirow[b]{2}{*}{$\mathrm{p}^{4}$} & \multicolumn{2}{|c|}{ in $\mathrm{kg}$ or $\%^{2}$} & \multicolumn{2}{|c|}{ in $\sigma_{\mathrm{a}}^{3}$} & \multirow[b]{2}{*}{$\mathrm{p}^{4}$} \\
\hline & $\alpha$ & SE & $\alpha$ & $\mathrm{SE}$ & & $\alpha$ & $\mathrm{SE}$ & $\alpha$ & SE & \\
\hline MY1L & -300 & 32 & -0.49 & 0.05 & 0.11 & -258 & 24 & -0.42 & 0.04 & 0.13 \\
\hline MY1-3L & -306 & 34 & -0.50 & 0.05 & 0.12 & -272 & 24 & -0.45 & 0.04 & 0.13 \\
\hline FY1L & 7.14 & 0.86 & 0.33 & 0.04 & 0.07 & 5.14 & 1.18 & 0.24 & 0.05 & 0.09 \\
\hline FY1-3L & 8.28 & 0.90 & 0.38 & 0.04 & 0.09 & 6.52 & 1.22 & 0.30 & 0.05 & 0.11 \\
\hline PY1L & -4.84 & 0.66 & -0.27 & 0.04 & 0.06 & -6.36 & 0.90 & -0.38 & 0.05 & 0.09 \\
\hline PY1-3L & -4.92 & 0.70 & -0.30 & 0.04 & 0.05 & -6.40 & 0.94 & -0.39 & 0.05 & 0.08 \\
\hline FP & 0.266 & 0.011 & 1.06 & 0.04 & 0.42 & 0.260 & 0.014 & 1.04 & 0.05 & 0.45 \\
\hline $\mathrm{PP}$ & 0.058 & 0.006 & 0.52 & 0.05 & 0.11 & 0.051 & 0.008 & 0.46 & 0.07 & 0.13 \\
\hline
\end{tabular}

All estimates are highly significant $(P<0.001)$.

${ }^{1}$ See Table 1.

${ }^{2}$ Estimates are expressed in $\mathrm{kg}$ per lactation ( $305 \mathrm{~d}$ ) for the yield traits.

${ }^{3}$ Estimates are expressed in additive genetic standard deviations. For expressing the estimates expressed in phenotypic standard deviations, the heritability shown in Table 1 can be used.

${ }^{4}$ Proportion of variance explained.

substitution effect for the 2 percentage traits. The proportion of the variance explained by the diallelic DGAT1 effect and by the diallelic DGAT1 effect together with the conditional QTL effect at position $0 \mathrm{cM}$ was estimated also.

\section{RESULTS}

The average substitution effect of the lysine variant (denoted as the $\mathrm{Q}$ allele) is positive for fat yield and the two percentage traits and negative for milk and protein yield (Table 2). For the yield traits they were slightly larger when the first three lactations were considered compared to the situations when only the first lactation was considered. Substitution effects estimated by model 2 (conditional QTL effect at the chromosomal position of DGAT1 included) are lower for milk and fat yield and higher for protein yield compared with the estimates from the simple model (only DGAT1 included). The latter estimates are in agreement with Thaller et al. (2003). Note that the values for the yield traits are approximately comparable with estimated breeding values only if they are multiplied by 2 .

The proportion of variance explained by the models is shown in Table 2 as well. When the conditional QTL effect, additional to the diallelic DGAT1 effect, was included, this proportion was increased at about 2 and $3 \%$ of the total variance for every trait investigated. Additionally, effects of the DGAT1 genotypes were estimated by a model that took the sire and the fixed effect of the DGAT1 genotype into account. The DGAT1 heterozygous group was slightly below the mean of the 2 homozygous groups for milk and protein yield, and slightly above for the other traits (not shown). However, these estimates cannot be interpreted as genotype effects described by Falconer and MacKay (1996), because the phenotypes used in this study represent purely additive effects. The small deviation of the DGAT1 heterozygous group from the mean of the two homozygous groups could be due to selection. The allele frequency of the lysine variant at DGAT1 is 0.53 ; this in agreement with Thaller et al. (2003).

No sire was homozygous QQ. This could partly be explained by the fact, that two of the three great-grandsires were homozygous qq at DGAT1. The haplotype analysis of the sires revealed that the marker allele " 1 " ("2") of KIEL_E8 was always on the same chromosome as the DGAT1 allele Q (q). The allele frequency of the allele 'l' of KIEL_E8 was 0.48. Around 98\% of the offspring, but all sires, showed corresponding genotypes at DGAT1 and KIEL_E8 (either Q,Q and 1,1; Q,q and 1,2 ; or $\mathrm{q}, \mathrm{q}$ and 2,2 ).

As expected, model 1 revealed genomewise significant effects for the QTL effect for all traits investigated. As results of this model only the plots of the test statistics along the chromosome are shown (Figures 1 to 5).

In model 2, the effect of DGAT1 was highly significant for all traits investigated (not shown). Genomewise significant effects $\left(P_{\text {genomewise }}<0.1\right)$ of the conditional QTL effect were found for fat percentage and protein percentage (Table 3). For fat and protein yield a chromosomewise significant effect was found (Table 3). For fat yield and percentage and protein yield the lower bound of the confidence interval was at the proximal end of the chromosome. For milk yield and protein percentage it was around $10 \mathrm{cM}$ (Table 3). The plots of the test 


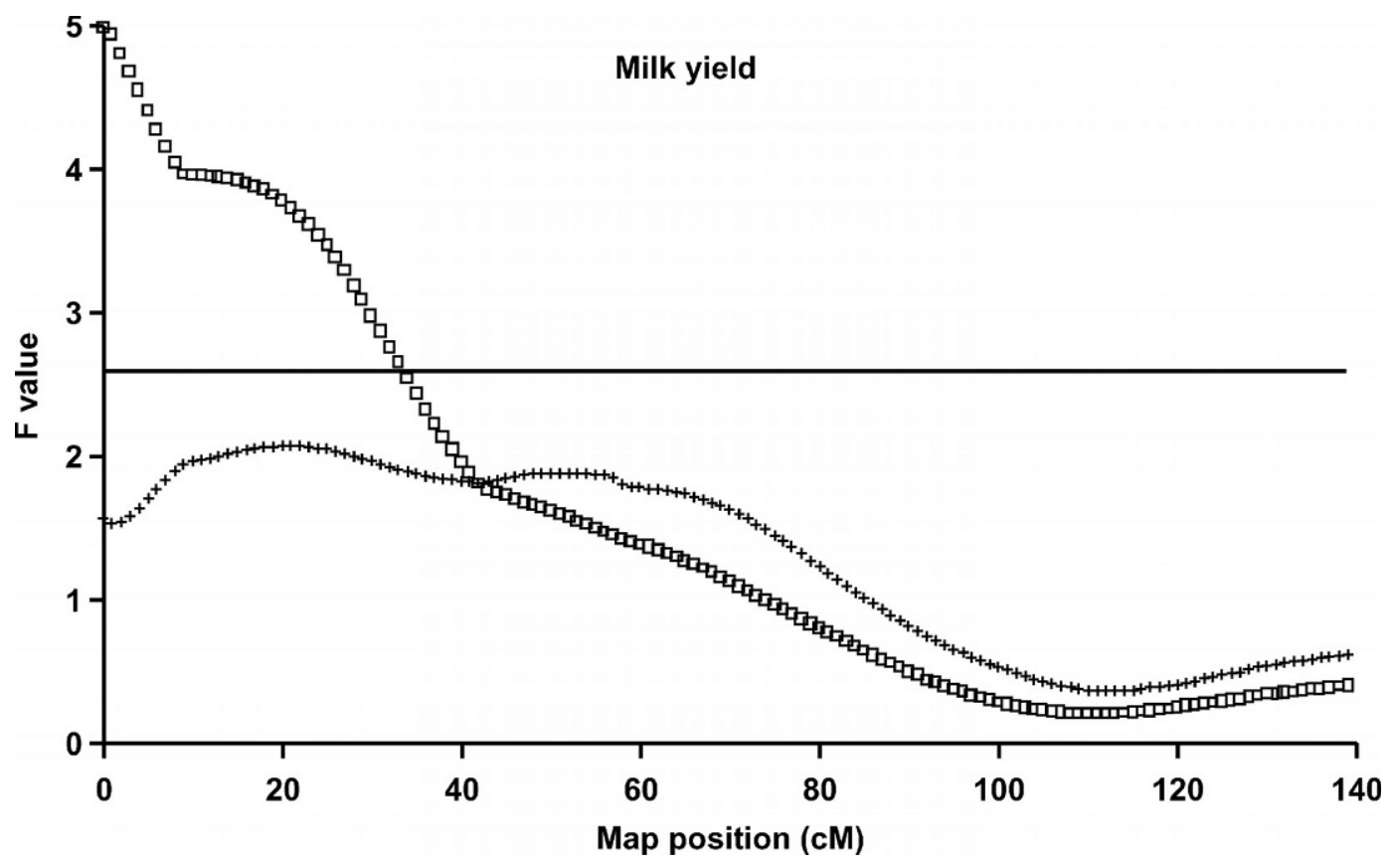

Figure 1. Test statistic profile on bovine chromosome 14 for milk yield first lactation for the QTL transition probability. ( $\square$ ) profile generated by model 1 (only QTL effect included), (+) profile generated by model 2 (conditional QTL effect and DGAT1 included). The horizontal lines are the $1 \%$ chromosomewise threshold values for model $2(+)$.

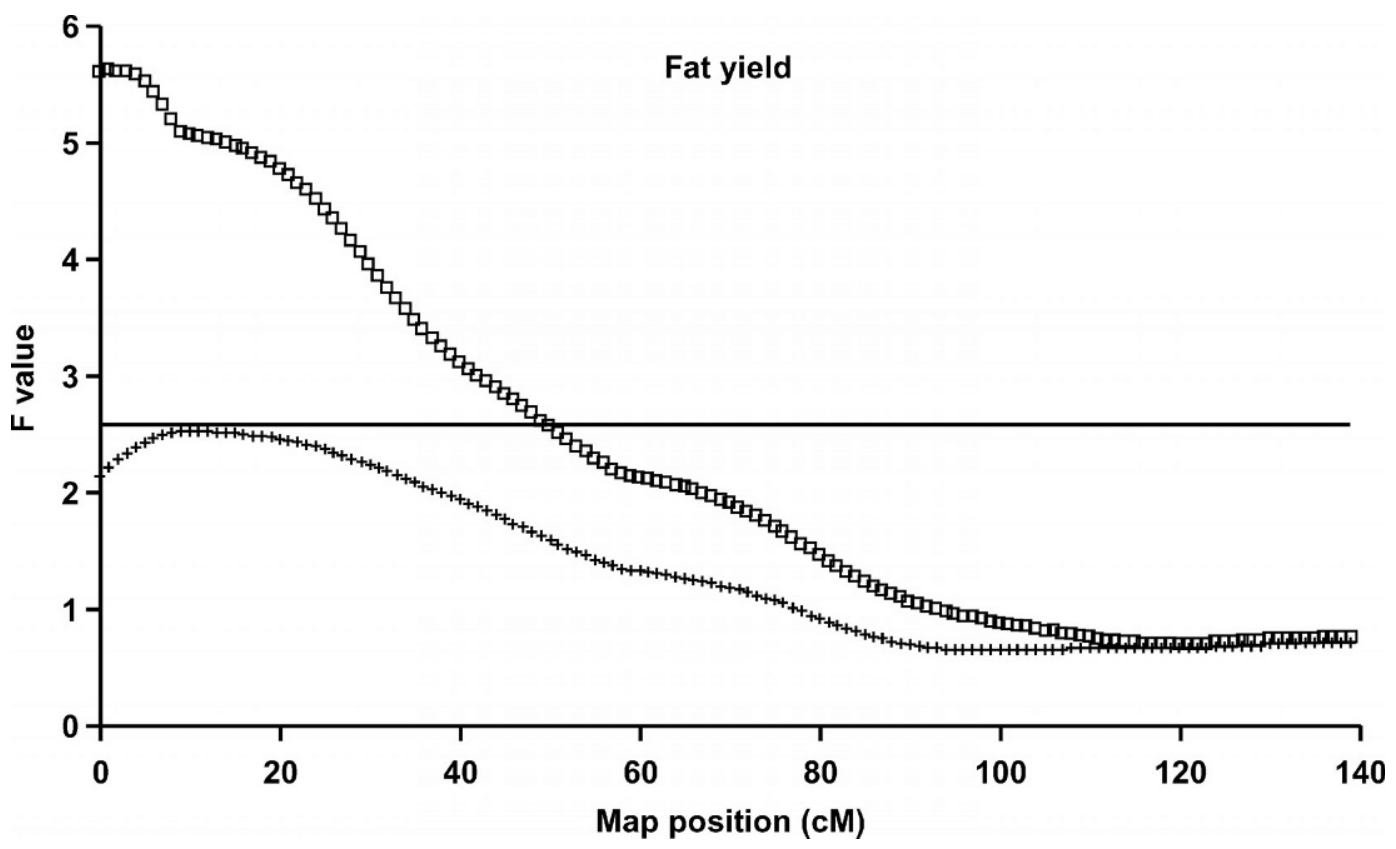

Figure 2. Test statistic profile on bovine chromosome 14 for fat yield first lactation for the QTL transition probability. ( $\square$ ) profile generated by model 1 (only QTL effect included), (+) profile generated by model 2 (conditional QTL effect and DGAT1 included). The horizontal lines are the $1 \%$ chromosomewise threshold values for model $2(+)$. 


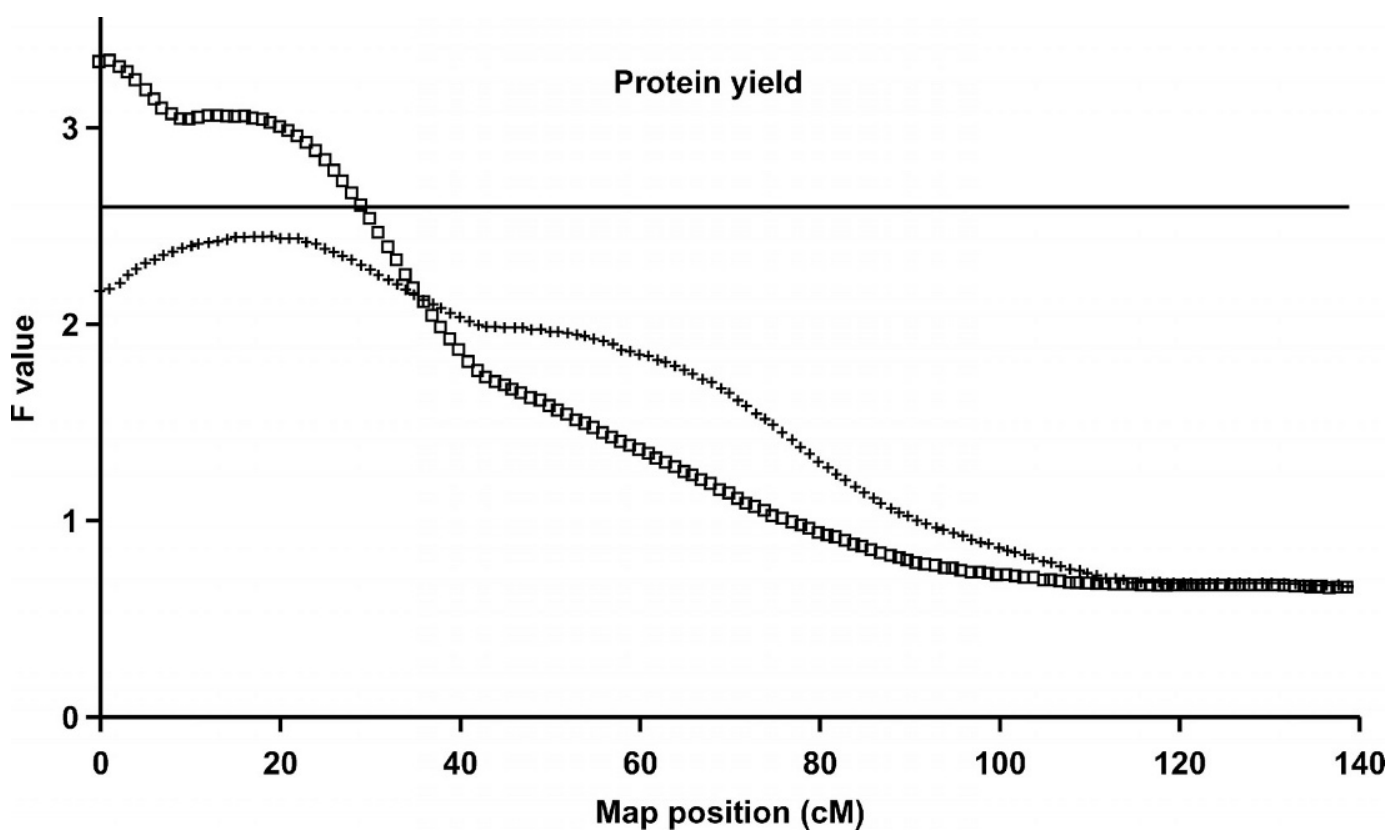

Figure 3. Test statistic profile on bovine chromosome 14 for protein yield first lactation for the QTL transition probability. ( $\square$ ) profile generated by model 1 (only QTL effect included), (+) profile generated by model 2 (conditional QTL effect and DGAT1 included). The horizontal lines are the $1 \%$ chromosomewise threshold values for model $2(+)$.

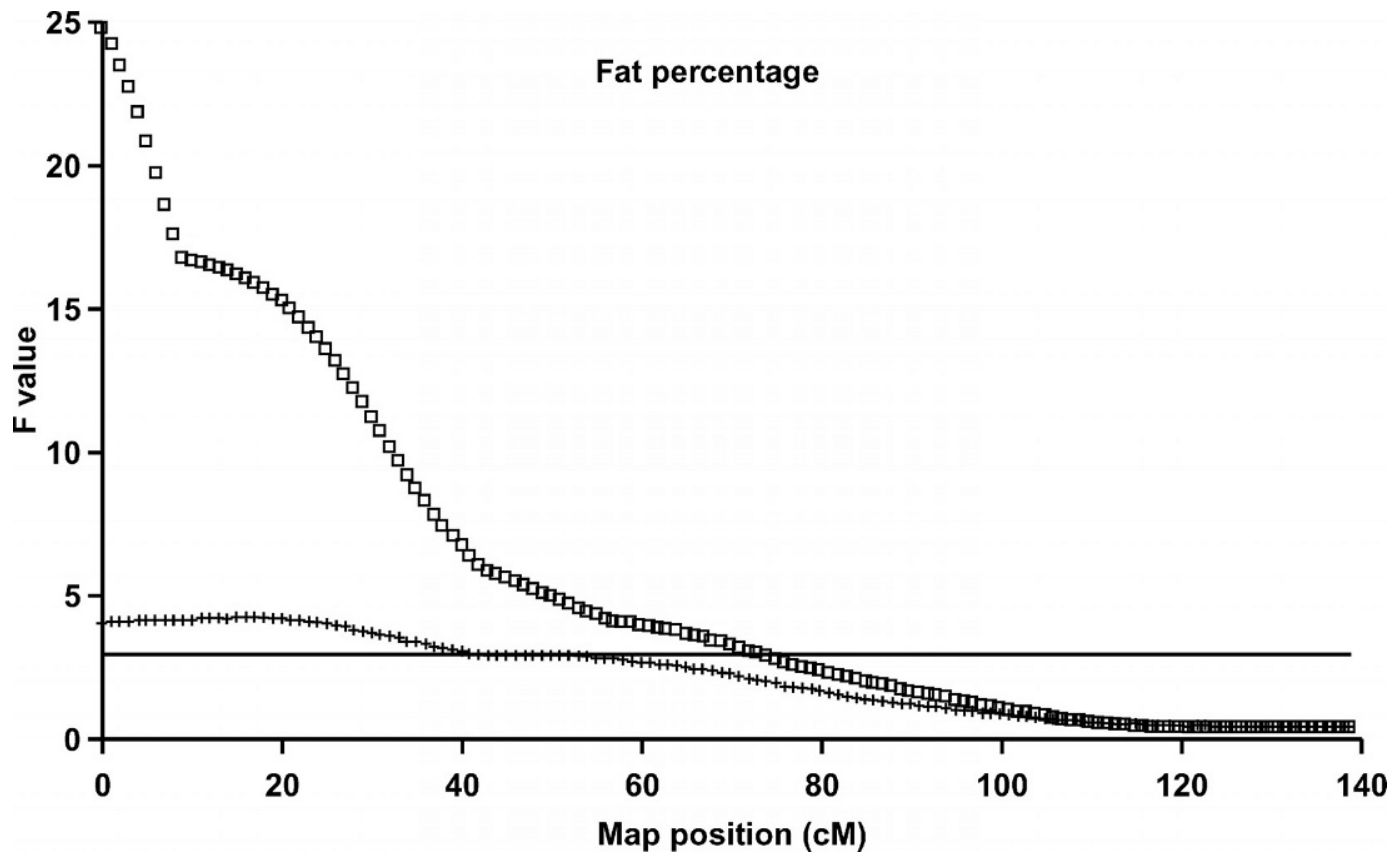

Figure 4. Test statistic profile on bovine chromosome 14 for fat percentage for the QTL transition probability. ( $\square$ ) profile generated by model 1 (only QTL effect included), (+) profile generated by model two (conditional QTL effect and DGAT1 included). The horizontal lines are the $1 \%$ chromosomewise threshold values for model $2(+)$. 


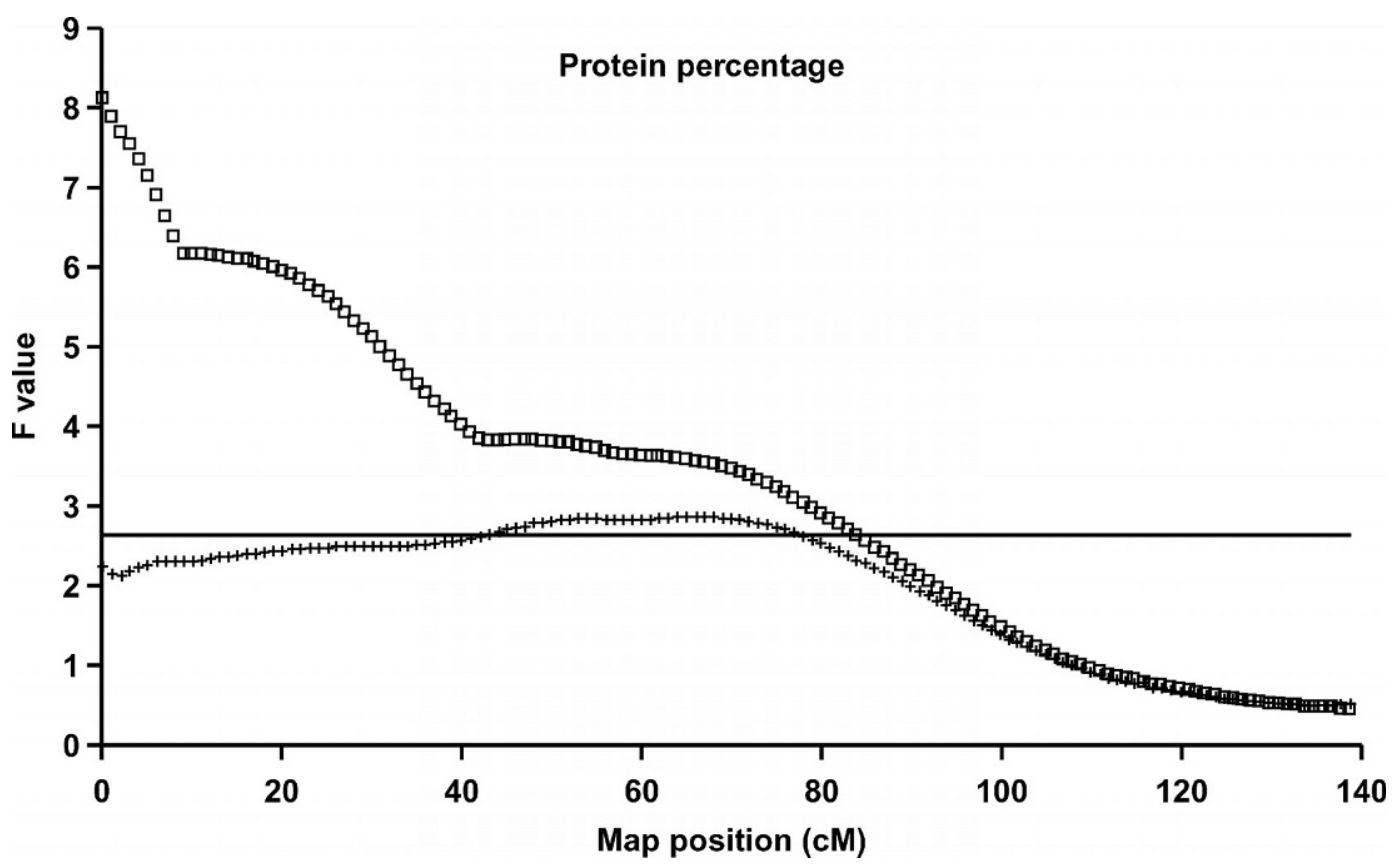

Figure 5. Test statistic profile on bovine chromosome 14 for protein percentage for the QTL transition probability. ( $\square$ ) profile generated by model 1 (only QTL effect included), (+) profile generated by model two (conditional QTL effect and DGAT1 included). The horizontal lines are the $1 \%$ chromosomewise threshold values for model $2(+)$.

statistic for the conditional QTL effect are shown in Figures 1 to 5 .

The results of the more detailed investigation at the chromosomal position of DGAT1 and KIEL_E8 by model three are presented in Table 4 . As expected, the effect of DGAT1 was highly significant for all traits. The conditional QTL showed a highly significant effect $\left(P_{\text {comparisonwise }}<0.01\right)$ for fat yield, fat percentage and for protein yield first three lactations and significant effects $\left(P_{\text {comparisonwise }}<0.05\right)$ for protein yield first lactation and protein percentage, but no significance for milk yield. The population regression term was not significant for any trait, indicating that there is no third allele of DGAT1, which shows a linkage disequilibrium only with one of the KIEL_E8 alleles.

\section{DISCUSSION}

Three different statistical models were applied to analyze the chromosome-14 genotypic data of a granddaughter design from the German Holstein dairy cattle population. The results are discussed in this section with respect to 3 possible additional sources of genetic variance at that particular chromosomal region that are at first additional allele(s) at the DGAT1 locus, but also a second QTL in linkage with DGAT1 and epistatic effects of DGAT1 with other genes. Given our null hypothesis in models 2 and 3 (i.e., the diallelic DGAT1 polymorphism is the only source of genetic variation at the proximal end of the bovine chromosome 14), the results of these models (Table 3 and 4) were surprising

Table 3. Results of model 2 with $F$ value, chromosomewise and genomewise error probabilities of the conditional QTL effect, estimated position of putative conditional QTL (distance from the first marker), and 95\% confidence interval (CI95).

\begin{tabular}{lllllr}
\hline Trait $^{1}$ & $F$ & $P_{\text {chromosomewise }}$ & $P_{\text {genomewise }}$ & Position (cM) & CI95 \\
\hline MY1L & 2.09 & 0.123 & NS & 21 & $13-76$ \\
MY1-3L & 2.10 & 0.107 & NS & 20 & $12-75$ \\
FY1L & 2.54 & 0.013 & NS & 9 & $2-75$ \\
FY1-3L & 2.61 & 0.012 & NS & 9 & $1-47$ \\
PY1L & 2.45 & 0.020 & NS & 18 & $3-75$ \\
PY1-3L & 2.61 & 0.011 & NS & 17 & $1-72$ \\
FP & 4.19 & $<0.001$ & $<0.001$ & 16 & $2-56$ \\
PP & 2.86 & 0.003 & 0.086 & 67 & $9-76$ \\
\hline
\end{tabular}

${ }^{1}$ See Table 1. 
Table 4. Results of model 3 with $F$ values and comparisonwise error probabilities of DGAT1, conditional QTL effect at position $0 \mathrm{cM}$, and population regression term (tp_pop).

\begin{tabular}{|c|c|c|c|c|c|c|}
\hline \multirow[b]{2}{*}{ Trait $^{1}$} & \multicolumn{2}{|c|}{ DGAT1 } & \multicolumn{2}{|c|}{ Conditional QTL effect } & \multicolumn{2}{|c|}{ tp_pop } \\
\hline & $F$ & $P_{\text {comparisonwise }}$ & $F$ & $P_{\text {comparisonwise }}$ & $F$ & $P_{\text {comparisonwise }}$ \\
\hline MY1L & 30.69 & $<0.001$ & 1.30 & 0.190 & 0.76 & 0.384 \\
\hline MY1-3L & 29.92 & $<0.001$ & 1.46 & 0.109 & 0.92 & 0.339 \\
\hline FY1L & 10.56 & $<0.001$ & 2.18 & 0.005 & 0.07 & 0.797 \\
\hline FY1-3L & 15.91 & $<0.001$ & 2.15 & 0.005 & 0.20 & 0.651 \\
\hline PY1L & 17.09 & $<0.001$ & 1.98 & 0.012 & 0.91 & 0.342 \\
\hline PY1-3L & 13.40 & $<0.001$ & 2.11 & 0.007 & 1.64 & 0.201 \\
\hline FP & 136.51 & $<0.001$ & 3.99 & $<0.001$ & 1.29 & 0.257 \\
\hline PP & 26.02 & $<0.001$ & 1.92 & 0.016 & 0.38 & 0.537 \\
\hline
\end{tabular}

${ }^{1}$ See Table 1.

and led to rejection of the null hypothesis for fat and protein yields and percentages. Also, similar values for the lysine allele substitution effect of the 2 models (one with and one without the conditional QTL effect at position 0 ) under the null hypothesis would be expected. However, these estimates are different (Table 2). It seems, that at least for fat and protein yield and percentages there is another source of variance. Three possible sources come to mind. There is at least one more allele segregating at the DGAT1 locus; there is another QTL in linkage with DGAT1; or the diallelic DGAT1 polymorphism interacts with another locus.

A visual inspection of the test statistic plots (Figures 1 to 5) revealed a pronounced maximum at the chromosomal position of DGAT1 (i.e., at $0 \mathrm{cM}$ ) for all traits, if DGAT1 was not included (model 1). Given the first explanation (at least one more allele at DGAT1) would be true, a similar shape of the test statistic plot would be expected, if DGAT1 was included (model 2). This is, however, only the case for fat percentage (Figure 4). For fat yield, protein yield, and protein percentage, the location at which the test statistic is maximal is more distal (Figures 1, 2, 3, and 5). Additionally, the lower confidence interval bound for protein percentage is around $10 \mathrm{cM}$ (Table 3). Following this, the hypothesis of further allele(s) segregating at DGAT1 seems to be more likely for the 2 fat traits than for the 2 protein traits. For the latter 2 traits, the theory of a second QTL more distal on the chromosome would be likely. It may be possible that these putative additional QTL were superposed by the strong DGAT1 effect, and therefore, not detected yet. Note, that none of the test statistic plots produced by model 2 (DGAT1 included) showed a pronounced maximum, and the estimated confidence intervals were large.

On the other hand, the (highly) significant effects of both, the DGAT1 and the conditional QTL, for the 2 fat traits and the 2 protein traits at the chromosomal position of DGAT1 (results from model 3; Table 4) can be interpreted as an argument for the multiple segre- gating DGAT1 allele theory affecting these traits. In Table 5 families are listed showing an additional significant effect for the 2 fat traits and the 2 protein traits, besides DGAT1, at this chromosomal position $(0 \mathrm{cM})$ for the conditional QTL (results from model 2). Sires that are DGAT1 heterozygous as well as sires that are DGAT1 homozygous showed significant effects for the conditional QTL. The corresponding regression coefficients are on a very high level (having in mind that they are likely overestimated), this is an indication that the extra effect, besides the diallelic DGAT1, has a major impact on the phenotypes.

Using a haplotype analysis with all markers, it was possible to derive the sires' haplotypes of the DGAT1 alleles (Table 5). For the DGAT1 heterozygous sires the estimates of the conditional QTL effect for the chromosome harboring the DGAT1 Q allele was positive for fat yield, fat and protein percentage, and also for protein yield. Unlike the two DGAT1 alleles, the putative third allele does not affect fat yield and protein yield in an antagonistic way. For example, the estimate of $6.71 \mathrm{~kg}$ fat yield and $4.27 \mathrm{~kg}$ protein yield in family F7 are both positive (Table 5). This finding is based on comparisonwise significant results only (Table 5). But this would also explain why the allele substitution effect of the lysine allele is higher for protein yield and lower for fat yield when it was estimated by a model where the conditional QTL effect was included (Table 2).

Putative other alleles might be a result of an undetected nonconservative mutation at another position of this exon or in another exon of DGAT1. Assuming that a further nonconservative mutation in this gene exists, 4 alleles (actually, 4 different haplotypes within this gene) are possible, resulting from combinations of 2 single mutations. Four alleles are possible at position $10433 / 10434$ assuming a combination of the 2 single mutations: an adenine/adenine to guanine/adenine substitution resulting in glutamine, and an adenine/adenine to adenine/cytosine substitution resulting in threonine. The procedure we used for scoring the DGAT1 
Table 5. Families with significant effects of the conditional QTL with family size (n), DGAT1 haplotype of the sire, estimate, and comparisonwise and experimentwise error probabilities at position $0 \mathrm{cM}$; results from model 2 (DGAT1 included).

\begin{tabular}{|c|c|c|c|c|c|}
\hline \multirow[b]{2}{*}{ Family (n) } & \multirow{2}{*}{$\begin{array}{l}\text { DGAT1 haplotype }{ }^{1} \\
\text { 1./2. chromosome }\end{array}$} & \multirow[b]{2}{*}{ Trait $^{2}$} & \multicolumn{3}{|c|}{ Conditional QTL effect } \\
\hline & & & estimate $^{3}$ & $P_{\text {comparisonwise }}$ & $P_{\text {experimentwise }} 4$ \\
\hline F1 (52) & $q / q$ & FP & 0.16 & 0.035 & NS \\
\hline \multirow[t]{2}{*}{ F2 (28) } & $q / q$ & FY1L & 10.48 & 0.001 & 0.016 \\
\hline & & $\mathrm{FP}$ & 0.24 & 0.002 & 0.032 \\
\hline \multirow[t]{2}{*}{ F3 (29) } & $\mathrm{Q} / \mathrm{q}$ & FY1L & 9.57 & 0.003 & 0.047 \\
\hline & & PY1L & 6.95 & 0.005 & 0.077 \\
\hline \multirow[t]{2}{*}{ F4 (56) } & $q / q$ & PY1L & 5.05 & 0.010 & NS \\
\hline & & FP & -0.20 & 0.001 & 0.016 \\
\hline F5 (42) & $\mathrm{Q} / \mathrm{q}$ & $\mathrm{FP}$ & 0.16 & 0.026 & NS \\
\hline \multirow[t]{3}{*}{ F6 (60) } & $\mathrm{Q} / \mathrm{q}$ & FY1L & 5.68 & 0.036 & NS \\
\hline & & PY1L & 4.45 & 0.028 & NS \\
\hline & & PP & 0.08 & 0.020 & NS \\
\hline \multirow[t]{4}{*}{ F7 (58) } & $\mathrm{Q} / \mathrm{q}$ & FY1L & 6.71 & 0.002 & 0.032 \\
\hline & & PY1L & 4.27 & 0.020 & NS \\
\hline & & FP & 0.11 & 0.048 & NS \\
\hline & & PP & 0.07 & 0.031 & NS \\
\hline
\end{tabular}

Only those families are listed that showed a significant effect of the conditional QTL effect $(P \leq 0.05)$.

${ }^{1}$ The chromosomal assignment of the DGAT1 alleles Q and q were done by haplotype analysis using all marker data, Q allele codes for lysine.

${ }^{2}$ See Table 1.

${ }^{3}$ The estimates are regression coefficients. The sign is positive (negative), if the first (second) chromosome increased the phenotype.

${ }^{4}$ Experimental error probabilities were calculated by the use of the Bonferroni correction assuming 16 families.

genotypes is RFLP based. Everything other than guanine/cytosine at these particular positions would be declared as adenine/adenine.

Furthermore, conservative mutations in exons and those detected in introns and in the UTR can influence the phenotype. There is evidence for alternative splicing of DGAT1 in human (http://www.ncbi.nlm.nih.gov/IEB/ Research/Acembly/av.cgi? $\mathrm{c}=$ Locusid\&org $=9606 \& \mathrm{~L}=$ 8694). Therefore, silent mutations could have an impact when located at positions necessary for correct splicing (Cartegni et al., 2002, Miriami et al., 2003).

Finally, Ludwig et al. (2002) reported 5 polymorphisms in the human DGAT1 promoter that affected several traits in Turkish women (i.e., body mass index, high density lipoprotein levels and blood pressure). This study indicates that a mutation in the DGAT1 promoter might also be responsible for the additional effect. To resolve this, further sequencing effort is needed. Based on our data it was not possible to postulate more than 3 alleles, because no sire showed the DGAT1 genotype QQ. It is also possible that both the multiple segregating allele theory and the hypothesis of a second QTL are correct.

The successful mapping of this QTL by many QTL experiments might be a result of approximate equal frequencies of the 2 DGAT1 alleles, because according to the Hardy-Weinberg equilibrium one half of the sires are expected to be heterozygous under equal allele fre- quencies at a diallelic locus. However, the expected number of heterozygous sires might be even higher when considering the putative third allele. In this study we genotyped 8 from 16 sires as DGAT1 heterozygous, but if the multiple allele theory at this locus is correct, three additional sires are segregating for fat percentage at this locus (sires F1, F2 and F4, Table 5).

The third hypothesis for explaining our results (interaction of DGAT1 with further genes) would be supported by detecting significant effects of the conditional QTL in DGAT1 heterozygous families. However, as mentioned above, homozygous families also revealed significant effects for the conditional QTL. Further, we applied a linear model taking the family, the DGAT1 genotype, the KIEL_E8 genotype and the interaction of these 2 loci as fixed effects into account. The results showed no significant effects for the interaction term (not shown). Of course, an interaction with other genes not in linkage with DGAT1 might exist resulting in increased or decreased effects. A statistically significant interaction of DGAT1 with other genes is not a likely explanation for the results found in this study. This is even more plausible because the effects of DGAT1 on the traits investigated were at a very high level.

\section{CONCLUSIONS}

We found strong evidence that the diallelic DGAT1 polymorphism K232A described by Grisart et al. (2002) 
and Winter et al. (2002) is not responsible for all genetic variance at the proximal end of the bovine chromosome 14 for fat yield, fat percentage, protein yield, and protein percentage in the German Holstein dairy cattle population. The results provided strong arguments for at least a third allele at the DGAT1 locus with major impact on fat yield and percentage and protein yield and percentage, a second QTL for these traits, or both. For research purposes, as well as for dairy cattle breeders who perform a DGAT1 gene assisted selection, it is important to know that the DGAT1 K232A is not the only polymorphism underlying the QTL for milk production at this particular chromosomal region.

\section{ACKNOWLEDGMENTS}

This research was supported by the German Cattle Breeders Federation (ADR) and the German Ministry of Education, Science, Research, and Technology (BMBF).

\section{REFERENCES}

Bennewitz, J., N. Reinsch, and E. Kalm. 2002. Improved confidence intervals in quantitative trait loci mapping by permutation bootstrapping. Genetics 160:1673-1686.

Bovenhuis, H., and C. Schrooten. 2002. Quantitative trait loci for milk production traits in dairy cattle. Proc. 7th World Congr. Genet. Appl. Livestock Prod. No. 09-07, Toulouse, France.

Brka, M., N. Reinsch, and E. Kalm. 2002. Is there linkage between supernumerary teats in cattle and BTA3 markers? Arch. Tierz. 45:429-432.

Cartegni, L., S. L. Chew, and A. R. Krainer. 2002. Listening to silence and understanding nonsense: Exonic mutations that affect splicing. Nature Rev. Genet. 3:285-298.

Churchill, G. A., and R. W. Doerge. 1994. Empirical threshold values for quantitative trait mapping. Genetics 138:963-971.

Coppieters, W., J. Riquet, J.-J. Arranz, P. Berzi, N. Cambisano, B. Grisart, L. Karim, F. Marcq, L. Moreau, C. Nezer, P. Simon, P. Vanmanshoven, D. Wagenaar, and M. Georges. 1998. A QTL with a major effect on milk yield and composition maps to bovine chromosome 14. Mamm. Genome 9:540-544.

Falconer, D. S., and T. F. C. MacKay. 1996. Introduction to Quantitative Genetics. 4th ed. Longman Scientific and Technical, New York, NY.

Farnir, F., B. Grisart, W. Coppieters, J. Riquet, P. Berzi, N. Cambisano, L. Karim, M. Mni, S. Moisio, P. Simon, D. Wagenaar, J. Vilkki, and M. Georges. 2002. Simultaneous mining of linkage and linkage disequilibrium to fine map quantitative trait loci in outbred half-sib pedigrees: Revising the location of a quantitative trait locus with major effect on milk production on bovine chromosome 14. Genetics 161:275-287.

Georges, M., L. Grobet, D. Poncelet, L. J. Royo, D. Pirottin, and B. Brouwers. 1998. Positional candidate cloning of the bovine $m h$ locus identifies an allelic series of mutations disrupting the myostatin function and causing double-muscling in cattle. Proc. 6th World Congr. Genet. Appl. Livestock Prod. 26:195-204.

Green, P., K. Falls, and S. Crooks. 1990. Documentation of CRIMAP, Version 2.4. Washington University School of Medicine, St. Louis, MO.

Grisart, B., W. Coppieters, F. Farnir, L. Karim, C. Ford, P. Berzi, N. Cambisano, M. Mni, S. Reid, P. Simon, R. Spelman, M. Georges, and R. Snell. 2002. Positional candidate cloning of a QTL in dairy cattle: Identification of a missense mutation in the bovine DGAT1 gene with major effect on milk yield and composition. Genome Res. 12:222-231.
Heyen, D. W., J. I. Weller, M. Ron, M. Band, J. E. Beever, E. Feldmesser, Y. Da, G. R. Wiggans, P. M. Vanraden, and H. A. Lewin. 1999. A genome scan for QTL influencing milk production and health traits in dairy cattle. Physiol. Genomics 1:65-175.

Kappes, S. M., J. W. Keele, R. T. Stone, T. S. Sonstegard, T. P. L. Smith, R. A. Mcgraw, N. L. Lopezcorrales, C. W. Beattie. 1997. A second-generation linkage map of the bovine genome. Genome Res. 7:235-249.

Knott, S. A., J. M. Elsen, and C. S. Haley. 1996. Methods for multiplemarker mapping of quantitative trait loci in half-sib populations. Theor. Appl. Genet. 93:71-80.

Looft, C., N. Reinsch, C. Karall-Albrecht, S. Paul, M. Brink, H. Thomsen, G. Brockmann, C. Kühn, M. Schwerin, and E. Kalm. 2001. A mammary gland EST showing linkage disequilibrium to a milk production QTL on bovine chromosome 14. Mamm. Genome 12:646-650.

Ludwig, E. H., R. W. Mahley, E. Palaoglu, S. Özbayrakci, M. E. Balestra, I. B. Borecki, T. L. Innerarity, and R. V. Farese, Jr. 2002. DGAT1 promoter polymorphism associated with alterations in body mass index, high density lipoprotein levels and blood pressure in Turkish women. Clin. Genet. 62:68-73.

Miriami, E., H. Margalit, and R. Sperling. 2003. Conserved sequence elements associated with exon skipping. Nucleic Acids Res. 31:1974-1983.

Reents, R., J. Jamrozik, L. R. Schaeffer, J. C. M. Dekkers. 1995. Estimation of genetic parameters for test day records of somatic cell score. J. Dairy Sci. 78:2847-2857.

Reinsch, N. 1999. A multiple-species, multiple-project database for genotypes at codominant loci. J. Anim. Breed. Genet. 116:425435.

Riquet, J., W. Coppieters, N. Cambisano, J.-J. Arranz, P. Berzi, K. Davis, B. Grisart, F. Farnir, L. Karim, M. Mni, P. Simon, F. Taylor, P. Vanmanshoven, D. Wagenaar, J. E. Womack, and M. Georges. 1999. Identity-by-descent fine-mapping of QTL in outbred populations: Application to milk production in dairy cattle. Proc Natl. Acad. Sci. USA 96:9252-9257.

Robbins, L. S., J. H. Nadeau, K. R. Johnson, M. A. Kelly, L. RoselliRehfuss, E. Baack, K. G. Mountjoy, and R. D. Cone. 1993. Pigmentation phenotypes of variant extension locus alleles result from point mutation that alter MSH receptor function. Cell 72:827834.

Spelman, R., C. A. Ford, P. McElhinney, G. C. Gregory, and R. G. Snell. 2002. Characterization of the DGAT1 gene in the New Zealand dairy population. J. Dairy Sci. 85:3514-3517.

Thaller, G., W. Krämer, A. Winter, B. Kaupe, G. Erhardt, and R. Fries. 2003. Effects of DGAT1 variants on milk production traits in German cattle breeds. J. Anim. Sci. 81:1911-1918.

Thomsen, H., N. Reinsch, N. Xu, C. Looft, S. Grupe, C. Kühn, G. A. Brockmann, M. Schwerin, B. Leyhe-Horn, S. Hiendleder, G. Erhardt, I. Medjugorac, I. Russ, M. Förster, B. Brenig, F. Reinhardt, R. Reents, J. Blümel, G. Averdunk, and E. Kalm. 2000. A male bovine linkage map for the ADR granddaughter design. J. Anim. Breed. Genet. 117:289-306.

Winter, A., W. Krämer, F. A. O. Werner, S. Kollers, S. Kata, G. Durstewitz, J. Buitkamp, J. E. Womack, G. Thaller, and R. Fries. 2002. Association of a lysine-232/alanine polymorphism in a bovine gene encoding acyl-CoA:diacylglycerol acyltransferase (DGAT1) with variation at a quantitative trait locus for milk fat content. Proc. Natl. Acad. Sci. 99:9300-9305.

\section{Appendix A. Estimating the Variance of the Daughter Yield Deviation}

The variance of a sire's daughter yield deviation (DYD) was estimated from the covariance matrix of the yield deviations from its daughters. For the yield deviations of the first lactation this matrix is a square matrix with dimensions $\mathrm{n} \times \mathrm{n}$ where $\mathrm{n}$ is the number 
of daughters of sire. Assuming that the yield deviations are not corrected for the permanent environment, the elements of the diagonal are:

$$
\sigma_{a}^{2}+\sigma_{p}^{2}+\frac{1}{n t m_{i}} \sigma_{e}^{2}
$$

where $\sigma_{a}^{2}, \sigma_{p}^{2}$, and $\sigma_{e}^{2}$ are the additive genetic, permanent environment and residual variance of the first lactation and $n \mathrm{~nm}_{\mathrm{i}}$ is the number of test milking of daughter $\mathrm{i}$ in the first lactation. The elements of the off-diagonal are:

$$
\frac{1}{4} \sigma_{a}^{2}
$$

which is the genetic covariance of observations between half-sibs. According to Falconer and MacKay (1996) it is possible to factor out the phenotypic variance $\left(\sigma_{\text {phenotypic }}^{2}\right)$. After little algebra the formula for estimating the variance of the DYD for the first lactation of a sire can be written in a more convenient form as:

$$
\begin{gathered}
\operatorname{Var}\left[D Y D_{1 . \text { lactation }}\right]=\left\{\frac{1}{n} h^{2}+\frac{1}{n} p^{2}+\frac{1}{n^{2}}\left(1-h^{2}-p^{2}\right)\right. \\
\left.* \sum_{i=1}^{n} \frac{1}{n t m_{i}}+\frac{n-1}{n} \frac{1}{4} h^{2}\right\} * \sigma_{\text {phenotypic }}^{2}
\end{gathered}
$$

where $\mathrm{h}^{2}$ and $\mathrm{p}^{2}$ are the heritability and the permanent environment of the first lactation.

The estimation of the variance of the DYD for more than one lactation will be demonstrated in a short example. Assume a sire has 2 daughters, one with observations in the first 2 and one only in the first lactation. Further, assume that the yield deviations were not corrected for the effect of the permanent environment. The covariance matrix can be written as:

$$
\begin{gathered}
\operatorname{Var}\left[D Y D_{1-j l a c t a t i o n}\right]= \\
{\left[\begin{array}{ccc}
\sigma_{a 1}^{2}+\sigma_{p 1}^{2}+\frac{1}{n t m_{1,1}} \sigma_{e 1}^{2} & \sigma_{a 1, a 2}+\sigma_{p 1, p 2} & \frac{1}{4} \sigma_{a}^{2} \\
\sigma_{a 1, a 2}+\sigma_{p 1, p 2} & \sigma_{a 2}^{2}+\sigma_{p 2}^{2}+\frac{1}{n t m_{1,2}} \sigma_{e 2}^{2} & \frac{1}{4} a_{a 1, a 2} \\
\frac{1}{4} \sigma_{a}^{2} & \frac{1}{4} a_{a 1, a 2} & \sigma_{a 1}^{2}+\sigma_{p 1}^{2}+\frac{1}{n t m_{2,1}} \sigma_{e 1}^{2}
\end{array}\right],}
\end{gathered}
$$

where $\sigma_{a j}^{2}, \sigma_{p j}^{2}$, and $\sigma_{e j}^{2}$ are the additive genetic, permanent environment and residual variance of lactation $j$, respectively, $\sigma_{a j, a j}{ }^{\prime}$ and $\sigma_{p j, p j} j^{\prime}$ are the covariance of the additive genetic and permanent environment of lactation $\mathrm{j}$ and $\mathrm{j}^{\prime}\left(\mathrm{j} \neq \mathrm{j}^{\prime}\right)$, respectively, and $\mathrm{ntm}_{\mathrm{ij}}$ is the number of test milking of cow i in lactation $j$. Extending the formula to more daughters and more lactations is straightforward. In the present study, the genetic parameters for both covariance matrices were taken from Reents et al. (1995).

\section{Appendix B: Estimating Allele Frequencies}

Allele frequencies for the marker KIEL_E8 and the DGAT1 polymorphism were estimated by maximum likelihood using the following log-likelihood function (Brka et al., 2002):

$$
\begin{aligned}
\ln L=\sum_{i=1}^{n} n_{i} \ln p_{i}+\sum_{i=1}^{n} \sum_{j=i+1}^{n} \frac{1}{2} n_{i j} \ln \left(p_{i}+p_{j}\right), \\
\text { with } p_{n}=1-\sum_{i=1}^{n-1} p_{i}
\end{aligned}
$$

where $\mathrm{n}$ is the number of distinct alleles at the marker under consideration, $n_{i}$ is the number of the ith allele from founder animals (i.e., either from founder sires or unequivocally descending from unknown dams), $\mathrm{n}_{\mathrm{ij}}$ is the number of half-sibs which share the same heterozygous genotype with their sire. 